\title{
Recommendations of Lifestyle Modification According to a Survey of First-Year University Students
}

\author{
Junko Nakanishi ${ }^{a}$, b, Yasunori Suematsu ${ }^{a}$, Tadaaki Arimura ${ }^{a}$, Takashi Kuwano ${ }^{a}$, \\ Yuhei Shiga ${ }^{\text {a }}$ Ken Kitajima ${ }^{\text {a }}$, Natsumi Morito ${ }^{c}$, Takanobu Nii ${ }^{\text {, }}$, \\ Keijiro Saku a, e, Shin-ichiro Miura, a, e,
}

\begin{abstract}
Background: We analyzed what kind of lifestyle modification firstyear university students need based on the results of a health-consciousness survey conducted in first-year students immediately after they entered a university.

Methods: This population-based cross-sectional study used a "questionnaire survey on lifestyle and health for promoting health" conducted in Japan in 2015. From among an initial pool of 3,912 students, we excluded 314 due to insufficient data. The remaining 3,598 students (2,206 males and 1,392 females) were divided into four groups according to body mass index (BMI) based on Japan Society for the Study of Obesity "Guidelines for the management of obesity disease 2016": low $(18.5>\mathrm{BMI})$, less than standard $(22.0>\mathrm{BMI} \geq 18.5)$, standard or higher $(25.0>\mathrm{BMI} \geq 22.0)$ and obesity $(\mathrm{BMI} \geq 25.0)$.

Results: Females had an ideal body image that was at a lower body weight regardless of their BMI. Males in the low BMI and obesity groups tended to be less aware of health issues. For each level of BMI, and in both males and females, the most frequent report of stress was "sometimes feel". The most frequent method for relieving stress was spending time with friends. Among males, those in the obesity group spent more time with "personal computers, televisions and games, etc." in a sitting position. When students were asked to rank which of their lifestyle habits needed the most improvement, "lack of exercise" was the highest, followed by "irregular schedule" and "dietary habits". In daily living behavior, a significant difference was observed for "exercise" among males, but not females.
\end{abstract}

Conclusion: The attitudes of both males and females regarding the

Manuscript submitted August 11, 2018, accepted September 1, 2018

aDepartment of Cardiology, Fukuoka University School of Medicine, Fukuoka, Japan

bJunshin Gakuen University, Fukuoka, Japan

${ }^{\mathrm{c}}$ Fukuoka University Hakata Station Clinic, Fukuoka, Japan

${ }^{d}$ Fukuoka University Health Care Center, Fukuoka, Japan

eDepartment of Molecular Cardiovascular Therapeutics, Fukuoka University School of Medicine, Fukuoka, Japan

${ }^{f}$ Corresponding Author: Shin-ichiro Miura, Department of Cardiology, Fukuoka University School of Medicine, 7-45-1 Nanakuma Jonan-ku, Fukuoka 8140180, Japan. Email: miuras@cis.fukuoka-u.ac.jp

doi: https://doi.org/10.14740/jocmr3574w importance of physical activity and the necessity of efforts to improve health are presented. Health education for university students based on the attitudes may be useful for the prevention of lifestyle-related diseases for themselves in the future and before they become parents.

Keywords: Lifestyle-related diseases; Gender; Obesity; Stress; Diet; Physical activity

\section{Introduction}

More than 20 years have passed since the Ministry of Health and Welfare proposed that the term "Adult diseases" be changed to "Lifestyle-related diseases". Currently, the prevention of lifestyle-related diseases is considered to be important. Regarding lifestyle-related diseases in children, in 1957 it was reported that obesity at a younger age tended to be associated with more extreme obesity in adulthood [1]. Metabolic syndrome in adulthood has been suggested to begin as early in childhood as age of 5 years [2]. A study in Japanese-Americans suggested that a Japanese lifestyle in childhood may reduce the risk of obesity, which is one of the risk factors for metabolic syndrome, in the future [3]. In Japan, lifestyle-related diseases have become a problem due to changes in lifestyle during childhood, and research on obesity and metabolic syndrome in school-aged children is proceeding [4, 5]. Levels of serum high-density cholesterol in junior high school students are related to a decrease in daily physical activity [6]. It has been reported that the changes in body mass index (BMI) in the early teens mainly reflect changes in muscle mass in males and fat volume in females [7]. In addition, since the balance between $\mathrm{BMI}$ and the accumulation of body fat greatly changes in pubertal boys [8], recommendations for physical activity, while taking gender into account, are needed for proper growth and development in childhood. The relationship between parents and their children is closely associated with the prevention of obesity [9]. In adolescence, poor-quality or too-short sleep is related to increases in BMI and body fat volume, as are unhealthy eating habits [10]. The onset of lifestyle-related diseases is thought to be related to conditions in the fetal and early postnatal periods according to DOHaD theory [11], which is based on the fetal programming hypothesis by Barker [12].

Therefore, to prevent lifestyle-related diseases, it is neces- 


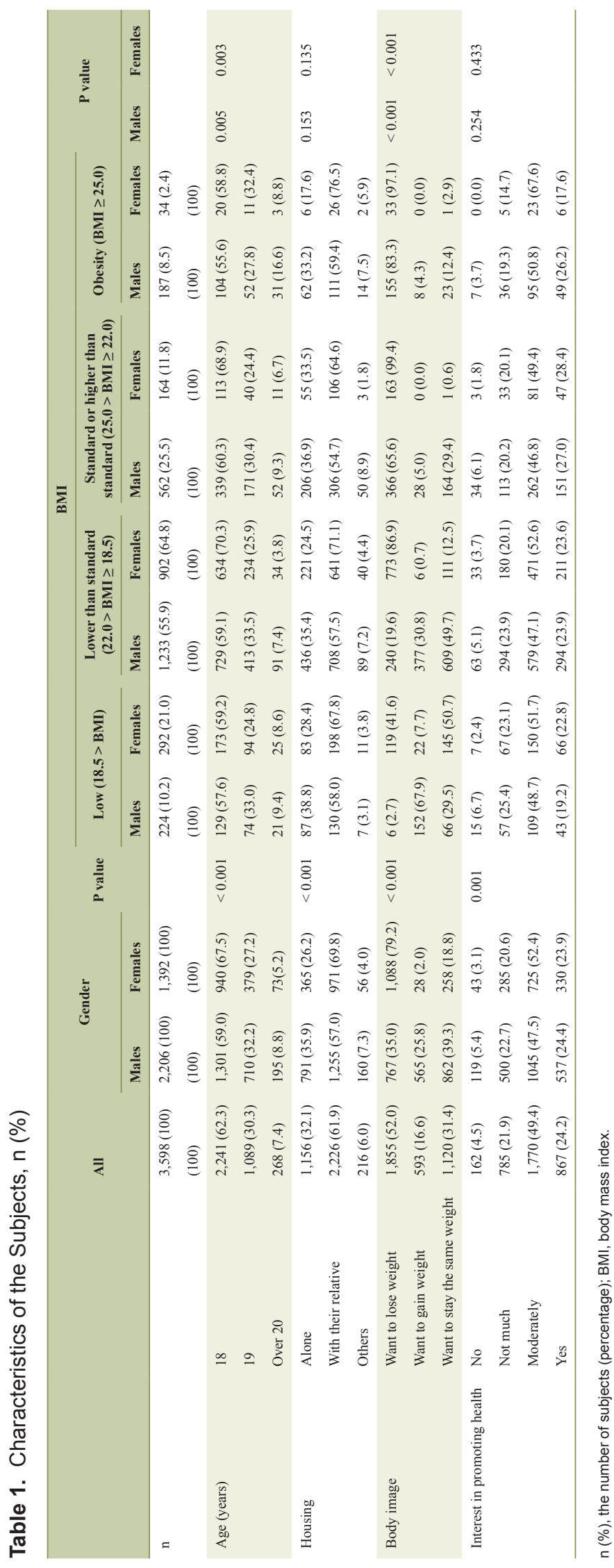

sary to give guidance to university students who are in the transition period from childhood to adulthood while taking into consideration the influence of gender differences on growth and development. In this study, we analyzed what kind of lifestyle modification they need based on the results of a healthconsciousness survey conducted in first-year students immediately after they entered a university.

\section{Patients and Methods}

\section{Participants and procedure}

Between 2010 and 2015, a "questionnaire survey on lifestyle and health for promoting health" was administered to incoming freshmen at Fukuoka University. About 24,000 students participated in the survey. Most students were between 18 and 20 years old, which is too young to be at risk for lifestyle-related diseases. The survey items included height, weight, BMI, pregnancy consciousness, concern for health dietary habits, health levels, sleeping habits, exercise habits, encouragement of physical activity, body image, smoking, stress and general feelings over the previous 2 weeks. Students were asked to rate their health levels from 0 point (lowest, a very bad health level) to 10 points (highest, a very good health level). Body image is a person's perception of the aesthetics of their own body, and it is how you see yourself when you look in the mirror or when you picture yourself in your mind. Students in the Department of Sports Science were excluded, since we considered that they would all be highly health-conscious and could have very strict BMI and body weight requirements depending on their sports specialty. Since this Department was not surveyed in 2015, we simply used the survey data from 2015 . Of the 3,912 students surveyed in 2015, we excluded 314 because of incomplete data. The remaining 3,598 students were divided into males and females (Table 1). They were also divided into four groups according to BMI based on the Japan Obesity Association "Obesity Disease Guideline 2016": low (18.5 > BMI), lower than standard (22.0 $>\mathrm{BMI} \geq 18.5)$, standard or higher than standard $(25.0>\mathrm{BMI} \geq 22.0)$ and obesity (BMI $\geq 25.0)$. This study was approved by the Institutional Review Board of Fukuoka University, and we analyzed questionnaire data retrospectively.

\section{Statistical analysis}

Statistical analyses were performed with IBM SPSS statistics version 24 (IBM, Chicago, IL, USA). Values are expressed as mean \pm standard deviation. Groups were compared by the chisquare test. $\mathrm{P}<0.05$ was considered statistically significant.

\section{Results}

\section{Characteristics of the subjects}

There were 2,206 males (61.3\%) and 1,392 females (38.7\%) 


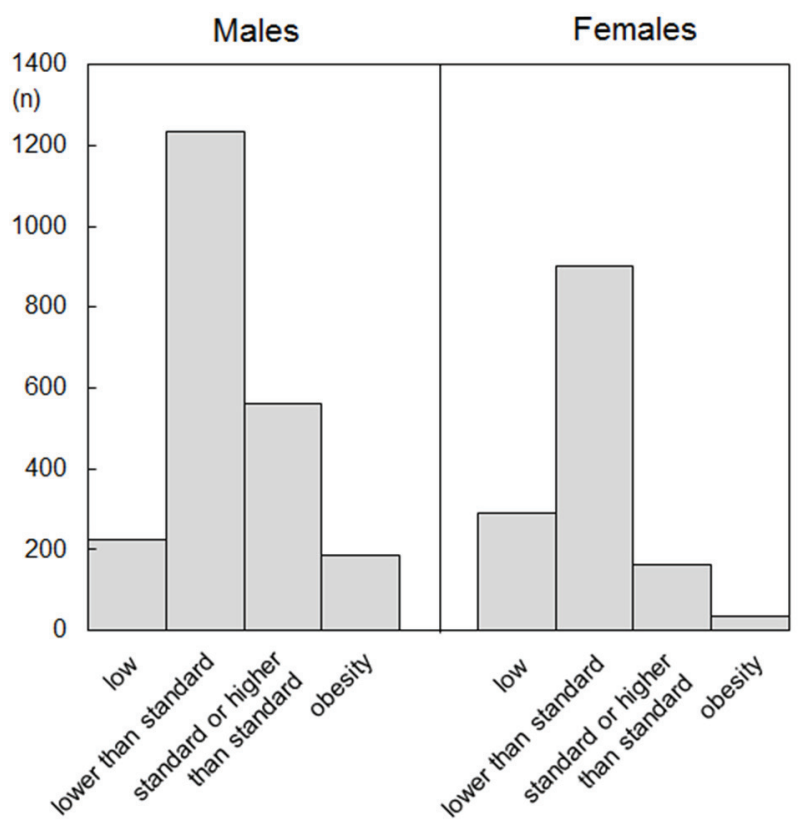

Figure 1. Histogram of body mass index (BMI) in male and female. The subjects were divided into four groups: low $(18.5>\mathrm{BMI})$, lower than standard (22.0 > BMI $\geq 18.5)$, standard or higher than standard (25.0 > $\mathrm{BMI} \geq 22.0)$ and obesity (BMI $\geq 25.0)$.

(Table 1). BMI, age, height and body weight in males and females were $21.4 \pm 2.8 \mathrm{~kg} / \mathrm{m}^{2}, 18.6 \pm 1.0$ years, $171.3 \pm 5.6$ $\mathrm{cm}$ and $62.7 \pm 9.2 \mathrm{~kg}$, and $20.1 \pm 2.2 \mathrm{~kg} / \mathrm{m}^{2}, 18.4 \pm 0.8$ years, $157.7 \pm 5.2 \mathrm{~cm}$ and $50.0 \pm 6.5 \mathrm{~kg}$, respectively. With regard to the BMI distribution, 224 males $(10.2 \%)$ and 292 females $(21.0 \%)$ were in the low group, 1,233 males (55.9\%) and 902 females $(64.8 \%)$ were in the lower than standard group, 562 males $(25.5 \%)$ and 164 females $(11.8 \%)$ were in the standard or higher group, and 187 males $(8.5 \%)$ and 34 females $(2.4 \%)$ were in the obesity group (Fig. 1). While both males and females tended to have a low BMI, $85.8 \%$ of females were lower than standard. In response to a prompt regarding housing, $57.0 \%$ males and $69.8 \%$ females answered that they lived in a "house with their relatives", and there were no significant differences in housing among the four BMI groups in males (P $=0.153)$ and females $(P=0.135)$. In response to the question "Do you have an interest in promoting health?", the most common answer in all four BMI groups for both males and females was "moderately". In response to the question "Do you want to lose weight or gain weight?" (Fig. 2), 67.9\% of males in the low BMI group wanted to gain weight, $49.7 \%$ in the lower than standard group wanted to stay the same weight, $65.6 \%$ in the standard or higher group wanted to lose weight, and $83.3 \%$ in the obesity group wanted to lose weight. Thus, the male students' body images were appropriate for their BMI levels. Among females, in the low BMI group, 50.7\% wanted to stay the same weight and $41.6 \%$ wanted to lose weight, $86.9 \%$ in the lower than standard group wanted to lose weight, $99.4 \%$ in the standard or higher than standard group wanted to lose weight, and $97.1 \%$ in the obesity group wanted to lose weight. Thus, females had an ideal body image that was at a lower weight regardless of their BMI (Fig. 2).

\section{Health levels}

The results of health levels were classified into quartiles as "low" (<3.9), "slightly low" ( $\geq 3.9$ and $<5.5)$, "slightly high" $(\geq 5.5$ and $<7.6)$, and "high" $(\geq 7.6)$ (Table 2). Among males, subjects with low health levels in the low BMI (31.8\%) and obesity $(47.8 \%)$ groups tended to have higher percentages, whereas there were no remarkable differences between the lower than standard or standard or higher groups and the standard group. Among females, there were no remarkable differences in health levels between the low BMI and lower than
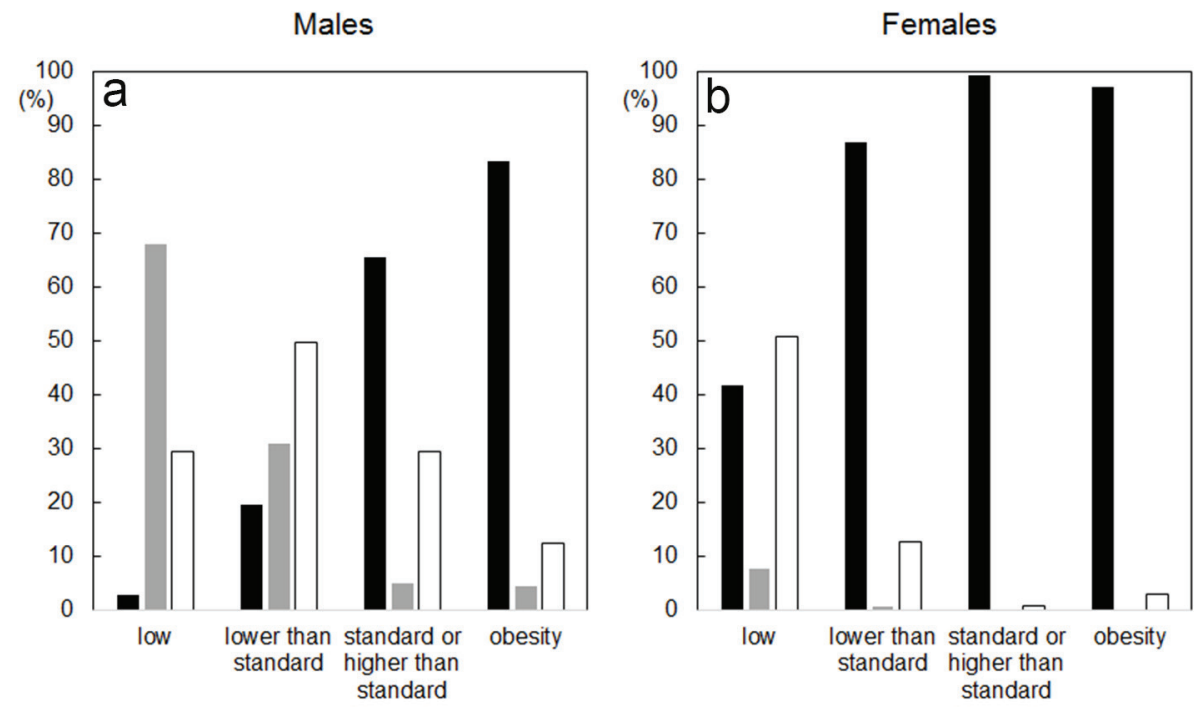

Figure 2. Body image in males (a) and females (b). The subjects were divided into four groups: low (18.5 > BMI), lower than standard (22.0 > BMI $\geq 18.5)$, standard or higher than standard (25.0 > BMI $\geq 22.0)$ and obesity (BMI $\geq 25.0)$. Closed, gray and open bars indicate "the subjects want to lose weight", "the subjects want to gain weight" and "the subjects want to stay the same weight", respectively. 


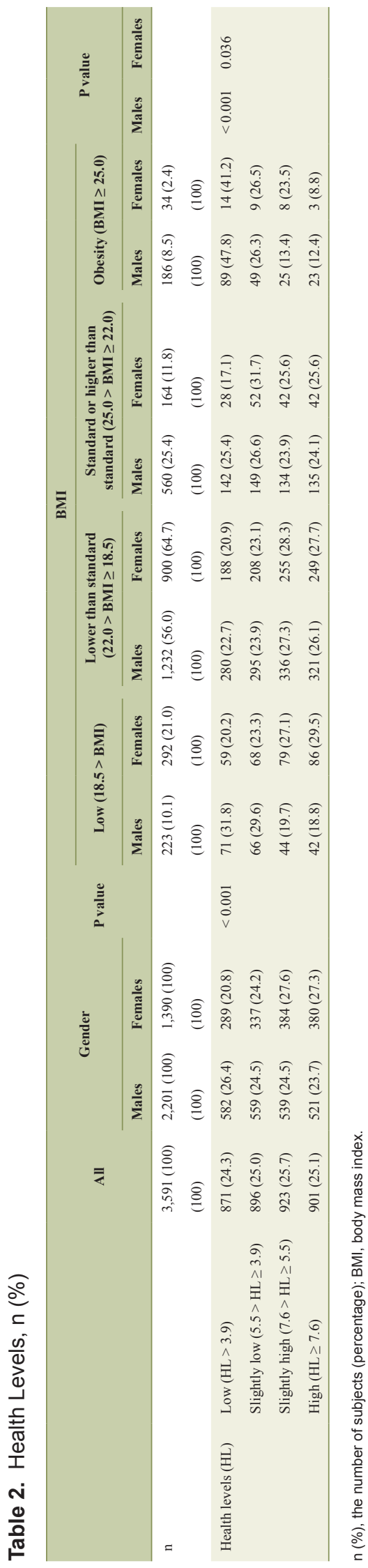

standard groups. In the female obesity group, $41.2 \%$ reported a low health level. In the standard or higher than standard female group, the most frequent self-assessment was a slightly low health level (31.7\%).

\section{Stress levels}

Among both males and females, in all BMI groups, the most commonly reported stress level was "sometimes feel" (Table 3 ). There were no significant differences in the feeling of stress between the BMI groups. Both males and females did not feel that they should reduce their stress levels. For both males and females, in all BMI groups, the most frequent cause of stress was "study at the university". Among females, there were significant differences between the BMI groups and "cause of stress", particularly "relationships with friends" $(\mathrm{P}=0.034)$ and "employment and career paths" $(\mathrm{P}=0.043)$; there were no similar differences in males. The most frequent method used to relieve stress was "spending time with friends", but only females showed a significant difference among the BMI groups $(\mathrm{P}=0.016)$. When "exercise and sports" was compared with "personal computers, televisions and games, etc." in a sitting position, males in the low BMI (42.9\%) and obesity $(43.9 \%)$ groups were more likely to respond the latter, whereas those in the standard or higher groups showed a high percentage of "exercise and sports" (40.6\%). In the female obesity group, "personal computers, televisions and games, etc." and "exercise and sports" accounted for $50.0 \%$ and only $2.9 \%$ of the responses, respectively. The other three BMI groups showed high percentages of "spending time with friends". There were many between-gender differences regarding feelings of stress, the cause of stress and the method used to reduce stress. However, there were no significant differences in the perceived "need to reduce stress" among the BMI groups in males $(\mathrm{P}=$ $0.400)$ and females $(P=0.258)$.

\section{Most needed lifestyle modification}

When students were asked to rate the aspects of their lifestyle that they most needed to change (Table 4), "lack of exercise" was the highest $(43.0 \%)$, followed by "irregular schedule" $(31.7 \%)$ and "poor dietary habits" $(30.7 \%)$. There were significant gender differences in "lack of exercise" $(\mathrm{P}<0.001)$ and "irregular schedule" $(\mathrm{P}=0.033)$. There were also significant differences in "lack of exercise" and "irregular schedule" among the BMI groups for both males and females. In addition, there was a significant gender difference in "not necessary" $(\mathrm{P}<0.001)$.

\section{Daily living activities}

There were significant gender differences in daily living activities except for "wake up" $(\mathrm{P}=0.849)$ (Table 5). Among males, significant differences were observed between the BMI groups for "exercise" $(\mathrm{P}<0.001)$ and "ingenuity of exercise" $(P=0.004)$, while similar differences were not seen among fe- 


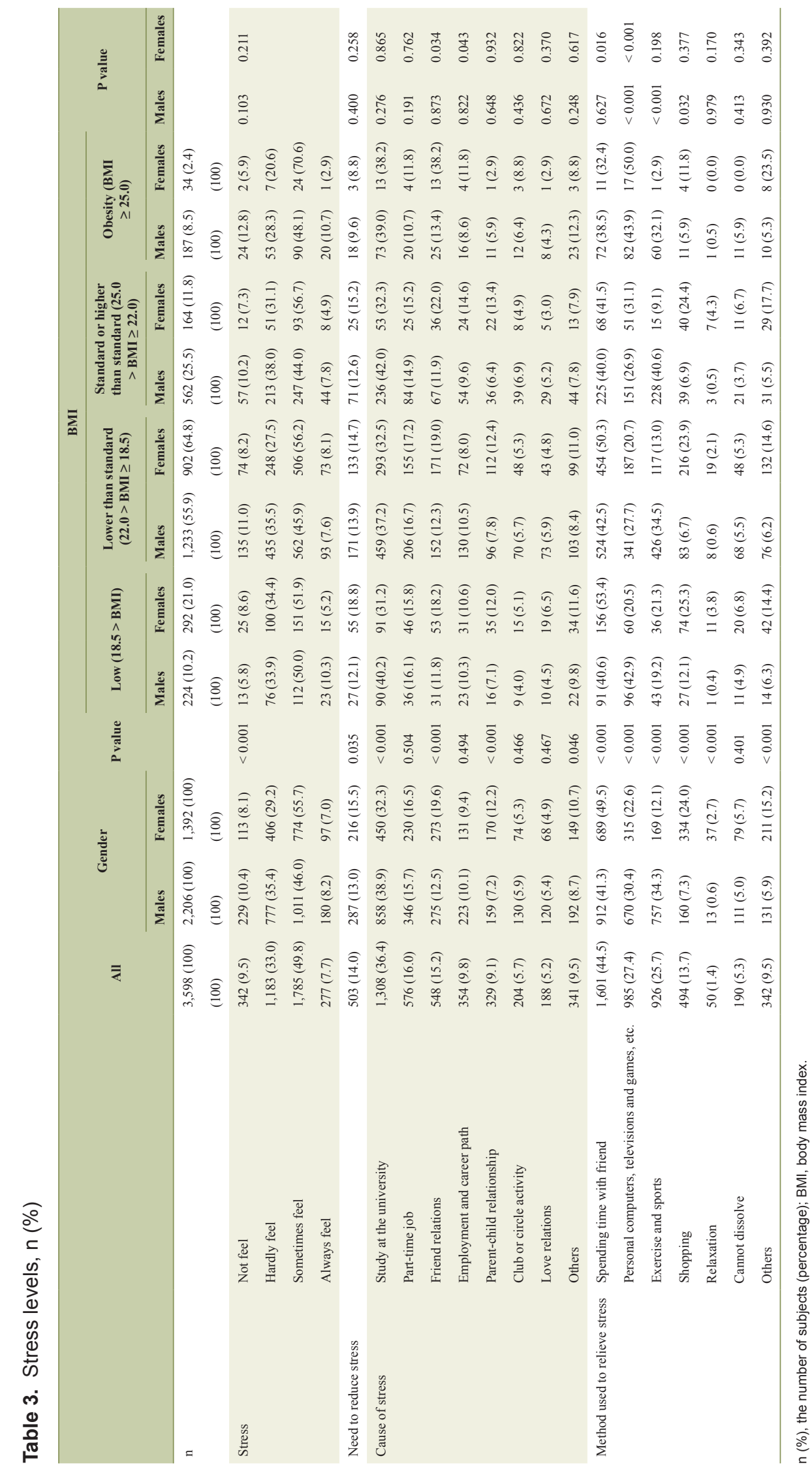




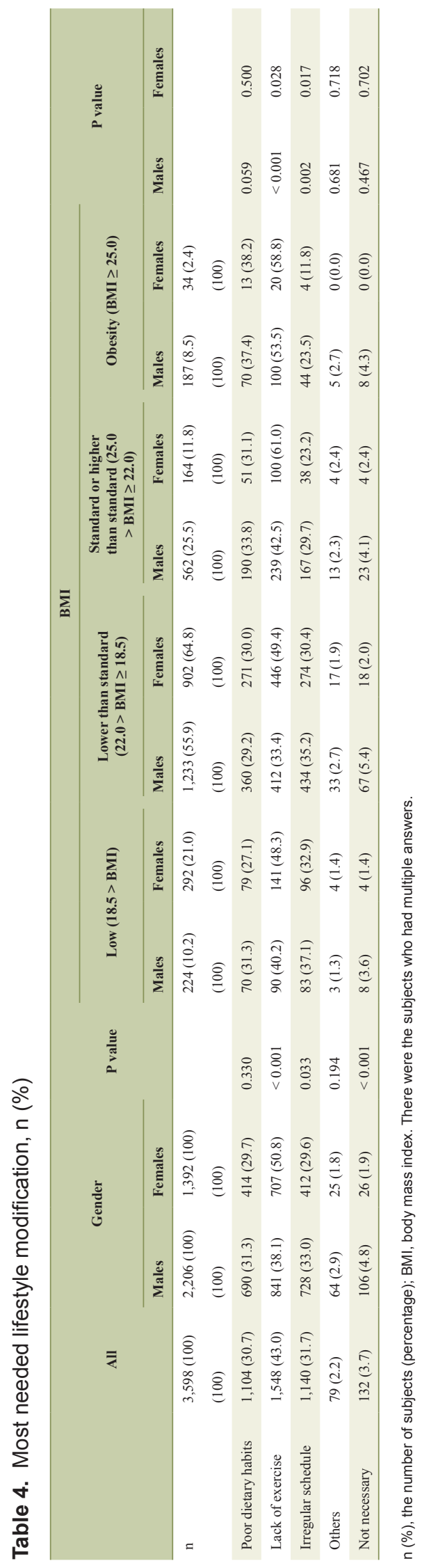

males. While "eat regular meals 3 times a day" was a frequent response among both males $(57.0 \%)$ and females (70.6\%), there were no differences among the BMI groups (males, $\mathrm{P}=$ 0.113 ; females, $\mathrm{P}=0.399$ ). With regard to sleep habits, $67.3 \%$ of males and $72.1 \%$ of females could sleep soundly, and about $30 \%$ of students (percentages of "unhealthy" plus "sometimes wake up") could not. Six hours of sleep was the most frequent response among both males (46.3\%) and females (42.9\%). With regard to exercise $(\mathrm{P}<0.001)$ and ingenuity of exercise $(\mathrm{P}<0.001)$, there were significant differences between males and females. Among low BMI males, $17.0 \%$ and $41.3 \%$ reported "not do it" and "hardly do it" exercise, respectively. In the other three groups, more than $60 \%$ responded that they "sometimes do it" or "do it well". With regard to "ingenuity of exercise", more than $60 \%$ of students in all four BMI groups responded "sometimes do it" or "always". Among females in all four BMI groups, more than $60-70 \%$ responded "not do it" or "hardly do it" for exercise, and more than $60-70 \%$ responded "sometimes do it" and "always" for ingenuity of exercise. In females, there were no significant differences among the BMI groups with respect to either exercise $(\mathrm{P}=0.438)$ or ingenuity of exercise $(\mathrm{P}=0.135)$.

\section{Discussion}

University students are expected to exhibit the lifestyle habits they adopted in their childhood environment. In this survey of the health-consciousness of first-year university students, significant differences were found in self-reported health levels, stress levels, the most needed lifestyle modification and daily living activities. It is very important to raise the awareness of new university students regarding health issues.

Among females in the low BMI group, $41.6 \%$ and $50.7 \%$ of students thought that they should ideally "want to lose weight" and "want to stay the same weight", respectively (Table 1). Regardless of their BMI, females, but not males, had a very strong desire to lose weight. Female university students have been reported to have a poor self-image a keen desire to lose weight, a tendency to have an eating disorder, a tendency to be on a diet, and to be strongly influenced by their friends [13]. In addition, a high level of malondialdehyde low-density lipoprotein was observed in remarkably lean girls. Since there is a significant correlation between leanness and the level of small dense low-density lipoprotein, it is important to instruct people to maintain an appropriate weight [14]. Lean male students had more subjective symptoms than normal and obese students. While lean female students were in worse health, they were as health-conscious as normal-weight students [15]. Women with a BMI less than 18.5 tend to deliver babies with lower birth weights than multiparturient women with a BMI from 18.5 to less than 25 [16]. In addition, low weight females from age 20 to after middle age have been associated with an increased risk of osteopenia [17]. In this study, although males tended to be less likely to be lean than females, $66.1 \%(10.2 \%$ low BMI and 55.9\% lower than standard) of male students desired to lose weight (Table 1). In a study of more than 350,000 Japanese subjects, BMI from 21 to 27 was associated with the 

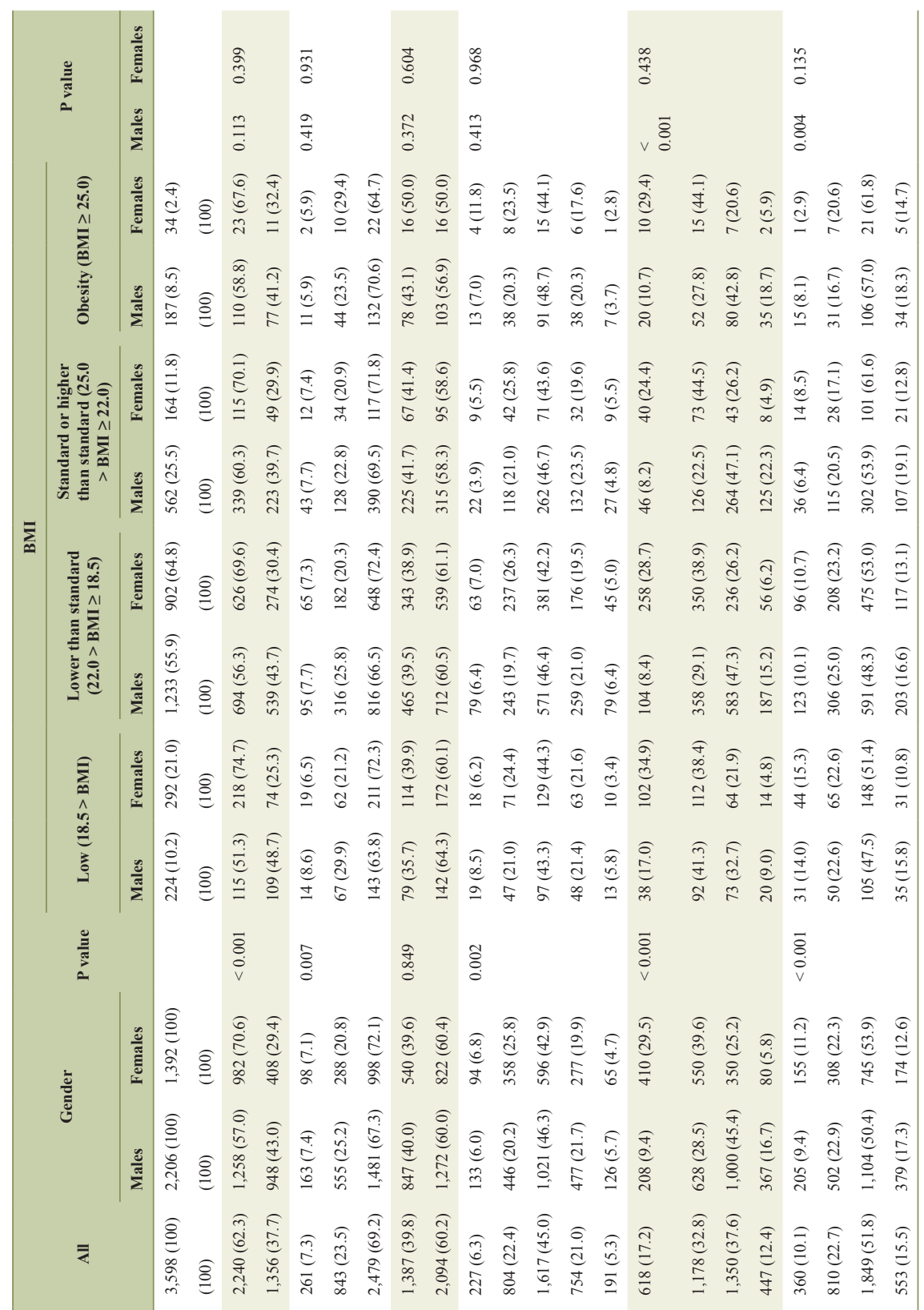

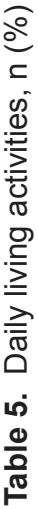

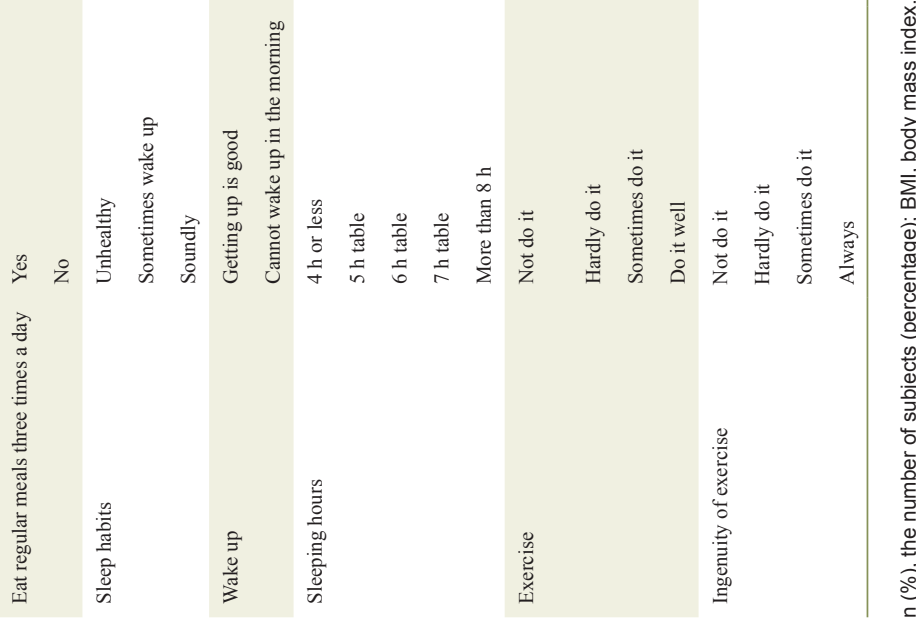


lowest risk of mortality [18]. Over the past 20 years, there has been a growing desire among not only female students but also male students to lose weight. This suggests that both males and females could benefit from health education at the university and in childhood. A longitudinal health education curriculum is needed to support students as they transition from childhood to adulthood.

Among both males and females, there was no significant difference in "stress" between the BMI groups, but a significant difference was recognized in "personal computer, television, games, etc." as "methods used to relieve stress" (Table $3)$. There was also a significant difference in "lack of exercise" as "most needed lifestyle modification" (Table 4). Groups characterized by low physical activities and/or behavior in a sitting posture have significantly higher rates of obesity [19]. In addition, students with moderate and high physical activity have a less frequent sitting posture, lower body fat and higher total energy consumption than students who sit for long hours or with low activity levels [20]. In our study, there was no significant association between "stress" and the BMI groups (Table 3). However, "personal computer, television, games, etc.", which involves sitting, was associated with "methods used to relieve stress". Since these students are aware of their lack of exercise, it is important to support continued physical activity. Studies of fatigue and pain related to Internet use by college students have reported effects on the eyes and neck [21]. Currently, personal computers are often used in early childhood, and "personal computer, television, games, etc." are activities that are done in the home, which means that students spend less time playing outside. Since "personal computer, television, game, etc." involves a sitting posture, "methods used to relieve stress" should be changed to "exercise and sports". Another strategy is to use "personal computer, television, games, etc." for a recommendation of exercise as a means. The development of software that can be used by both males and females to promote exercise using "personal computer, television, games, etc." may be important.

There was a significant difference between males and females with regard to "health levels" (Table 2). There were also significant differences in "exercise" (Table 5), and "exercise and sports" as "methods of relieving stress" (Table 3) between males and females. Although male students have more physical activities than female students, psychologically males showed lower health levels than females. Female students in the obese group self-reported "low" health, whereas more than half of females in the low BMI group considered their health to be "slightly high" or "high". Although females recognized their own "lack of exercise", it is necessary for females to understand that health levels are not good even if they are thin.

\section{Study limitations}

First, this study was cross-sectional. Second, we only examined students with regard to gender and BMI, and weight and height were self-reported. We did not examine the changes in BMI and other factors after admission. Third, the students surveyed were young adults who had not finished growing, and it is difficult to apply standard BMI values. The relationship between childhood indexes and adult BMI, such as the degree of obesity, Laurel index, Kaup index, etc., should be examined in a future study.

\section{Conclusions}

The lifestyle habits of first-year university students reflect their environments in childhood, and they may need help to understand their own health-related behavior and how to engage in more health-promoting activities for the prevention of lifestyle-related diseases in the near future. Since these students may become parents themselves, it is important that efforts are made to raise their health-consciousness. Health education for lifestyle modification is important not just for obese students, but also for lean students.

\section{Conflict of Interest}

KS and SM are Directors of NPO Clinical and Applied Science, Fukuoka, Japan. KS and SM received a grant from the Public Interest Incorporated Foundation of "Clinical Research Promotion Foundation" in Fukuoka, Japan, and part of this work was transferred to NPO Clinical and Applied Science, Fukuoka, Japan. KS has an Endowed Department of Molecular Cardiovascular Therapeutics (SM), Fukuoka University, supported by MSD Co., Ltd.

\section{References}

1. Mullins AG. The prognosis in juvenile obesity. Arch Dis Child. 1958;33(170):307-314.

2. Koskinen J, Magnussen CG, Sinaiko A, Woo J, Urbina E, Jacobs DR, Jr., Steinberger J, et al. Childhood age and associations between childhood metabolic syndrome and adult risk for metabolic syndrome, type 2 diabetes mellitus and carotid intima media thickness: the international childhood cardiovascular cohort consortium. J Am Heart Assoc. 2017;6(8):e005632.

3. Shiwa M, Yoneda M, Nakanishi S, Oki K, Yamane K, Kohno N. Japanese lifestyle during childhood prevents the future development of obesity among JapaneseAmericans. PLoS One. 2015;10(3):e0120804.

4. Munakata H, Sei M, Ewis AA, Umeno M, Sato Y, Nakano T, Sakamoto K, et al. Prediction of Japanese children at risk for complications of childhood obesity: gender differences for intervention approaches. J Med Invest. 2010;57(1-2):62-68.

5. Osawa H, Sugihara N, Ukiya T, Ishizuka Y, Birkhed D, Hasegawa M, Matsukubo T. Metabolic syndrome, lifestyle, and dental caries in Japanese school children. Bull Tokyo Dent Coll. 2015;56(4):233-241.

6. Hongo M, Hidaka H, Sakaguchi S, et al. Serum highdensity lipoprotein cholesterol level and lifestyle habits among Japanese Junior High School Students. Shinshu Med J. 2013;61:205-215.

7. Koeda S, Takahashi I, Umeda T, et al. Effects of changes 
in physique and lifestyle on bone mineral density in the early teens. Hirosaki Med J. 2012;63:28-37.

8. Fujii K, Tanaka N, Mishima T. Verification regarding changing construction in accumulation of fat for BMI based on change with age estimated from body composition balance. J Hum Ergol (Tokyo). 2013;42(1-2):31-44.

9. Kogawa T, Nishimura M, Kurauchi S, et al. Correlation between the parent-child relationship and obesity in adolescents. JPFNI. 2014;24:3-9.

10. Ferranti R, Marventano S, Castellano S, Giogianni G, Nolfo F, Rametta S, Matalone M, et al. Sleep quality and duration is related with diet and obesity in young adolescent living in Sicily, Southern Italy. Sleep Sci. 2016;9(2):117122.

11. Hanson M, Gluckman P. Developmental origins of noncommunicable disease: population and public health implications. Am J Clin Nutr. 2011;94(6 Suppl):1754S1758 S.

12. Barker DJ. The fetal and infant origins of adult disease. BMJ. 1990;301(6761):1111.

13. Matsumoto S, Kumano H, Sakano Y. Investigation of social influence on eating disorder tendencies and dieting behavior among female students. JABCT. 1999;25:11-23.

14. Ishikawa $\mathrm{K}$, Taira $\mathrm{E}$, Tada $\mathrm{M}$, et al. Studies on clinical characteristics and backgrounds of underweight and obese freshman for establishment of appropriate individual health guidance. Journal of the Faculty of Nursing, Iwate Prefectural University. 2012;14:13-20.

15. Kajita M, Takahashi T, Hayashi K, Fukuharu M, Sato
J, Sato Y. Self-esteem and mental health characteristics especially among lean students surveyed by University Personality Inventory. Psychiatry Clin Neurosci. 2002;56(2):123-129.

16. Suzuki K, Nomura K, Takenoshita S, Ando K, Kido M. Combination of parity and pre-pregnancy BMI and low birth weight infants among Japanese women of reproductive age. Ind Health. 2016;54(6):515-520.

17. Tatsumi Y, Higashiyama A, Kubota Y, Sugiyama D, Nishida Y, Hirata T, Kadota A, et al. Underweight young women without later weight gain are at high risk for osteopenia after midlife: the KOBE study. J Epidemiol. 2016;26(11):572-578.

18. Sasazuki S, Inoue M, Tsuji I, Sugawara Y, Tamakoshi A, Matsuo K, Wakai K, et al. Body mass index and mortality from all causes and major causes in Japanese: results of a pooled analysis of 7 large-scale cohort studies. J Epidemiol. 2011;21(6):417-430.

19. Kim Y, Barreira TV, Kang M. Concurrent associations of physical activity and screen-based sedentary behavior on obesity among US adolescents: A Latent Class Analysis. J Epidemiol. 2016;26(3):137-144.

20. Alghadir AH, Gabr SA, Iqbal ZA. Effects of sitting time associated with media consumption on physical activity patterns and daily energy expenditure of Saudi school students. J Phys Ther Sci. 2015;27(9):2807-2812.

21. Dol KS. Fatigue and pain related to internet usage among university students. J Phys Ther Sci. 2016;28(4):12331237. 